\title{
A young man with out-of-hospital cardiac arrest-it goes round and round
}

\author{
S. C. M. D. Panman · J. M. ter Maaten · Y. Blaauw
}

Published online: 31 July 2020

(c) The Author(s) 2020

A 24-year-old male patient presented at the emergency department after an out-of-hospital cardiac arrest. He had a witnessed arrest, after which basic life support was initiated by those present. An automated external defibrillator (AED), fetched by bystanders, delivered one shock, resulting in return of spontaneous circulation. His medical history involved palpitation complaints for which he visited the general practitioner's practice. No definitive diagnosis had been made yet. His family history was clear of sudden cardiac death or cardiomyopathies. The electrocardiogram (ECG) at presentation at the emergency department is shown in Fig. 1. He was subsequently admitted to the cardiac care unit, where he experienced re-

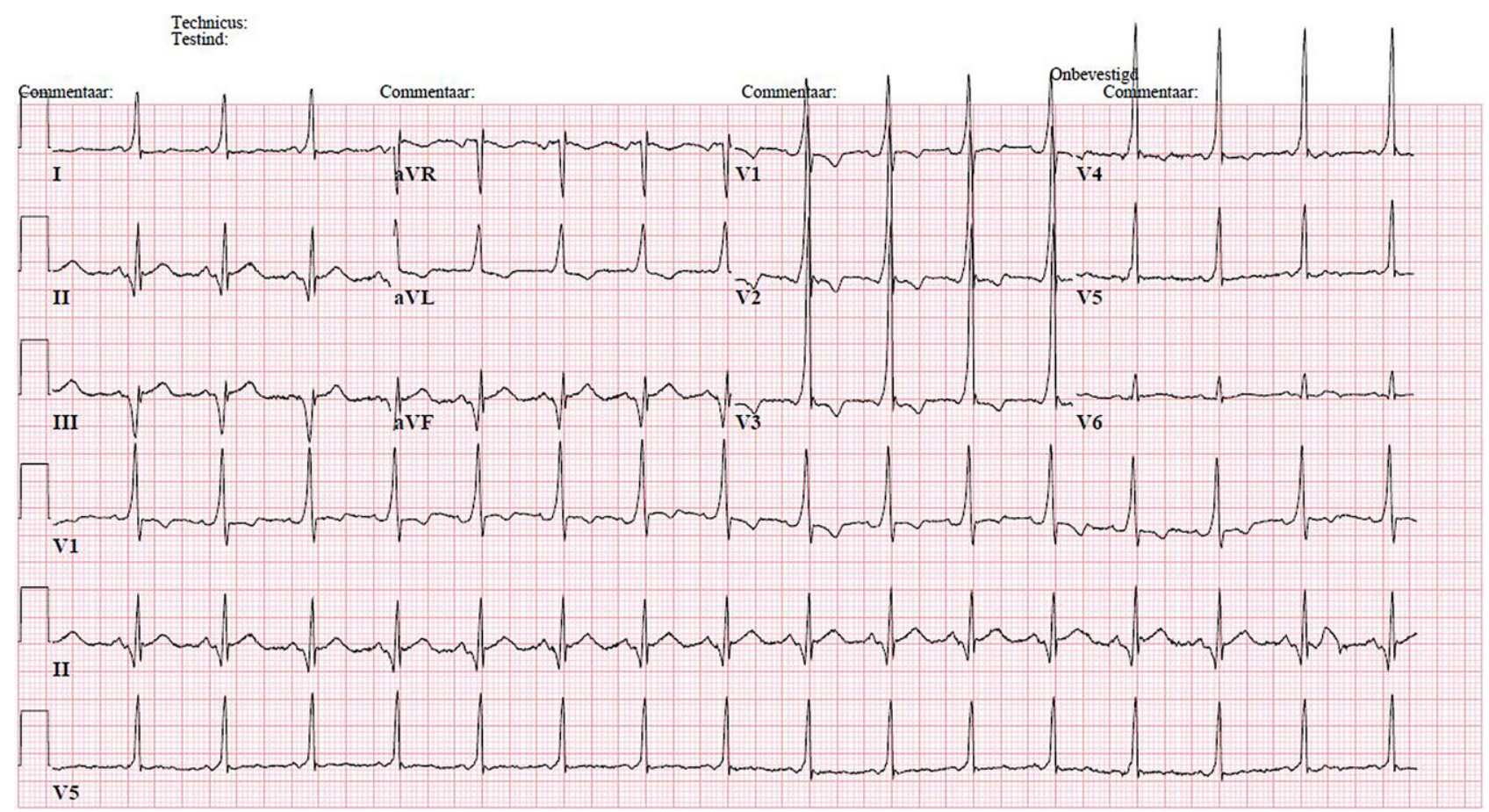

Fig. 1 The ECG at presentation at the emergency department

S. C. M. D. Panman $(\triangle) \cdot$ · J. M. ter Maaten $\cdot$ Y. Blaauw Department of Cardiology, University Medical Center Groningen, University of Groningen, Groningen, The Netherlands

s.c.m.d.panman@umcg.nl 


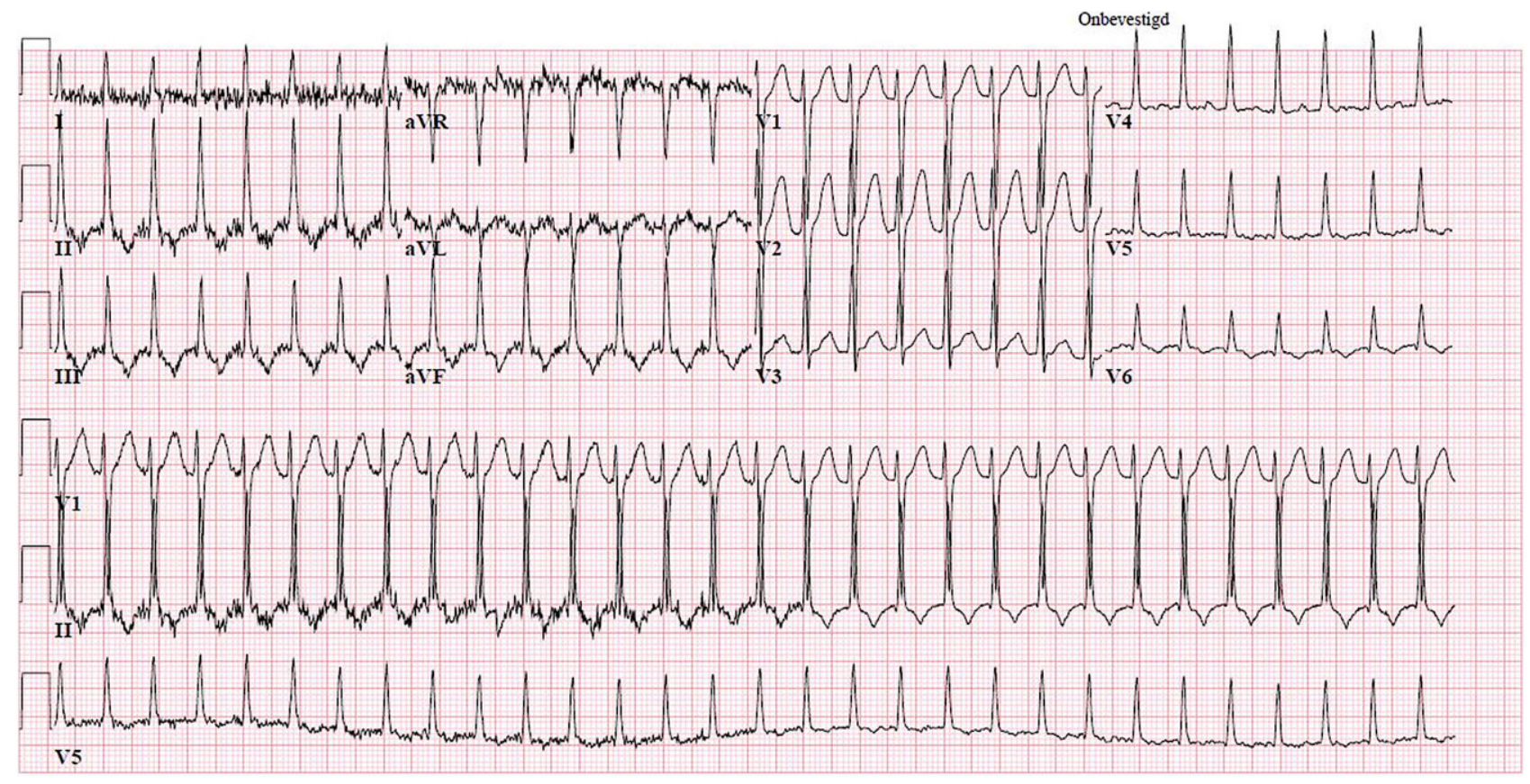

Fig. 2 The ECG during palpitations complaints at the cardiac care unit

current palpitations with stable haemodynamics. The ECG during palpitation complaints is shown in Fig. 2.

1. What is your diagnosis at this point?

2. What is the suggested therapy?

\section{Answer}

You will find the answer elsewhere in this issue.

Open Access This article is licensed under a Creative Commons Attribution 4.0 International License, which permits use, sharing, adaptation, distribution and reproduction in any medium or format, as long as you give appropriate credit to the original author(s) and the source, provide a link to the Creative Commons licence, and indicate if changes were made. The images or other third party material in this article are included in the article's Creative Commons licence, unless indicated otherwise in a credit line to the material. If material is not included in the article's Creative Commons licence and your intended use is not permitted by statutory regulation or exceeds the permitted use, you will need to obtain permission directly from the copyright holder. To view a copy of this licence, visit http://creativecommons.org/licenses/by/4.0/. 